\title{
Mujeres migrantes fronterizas en Tarapacá a principios del siglo XXI. El cruce de las fronteras y las redes de apoyo ${ }^{1}$
}

\author{
Marcela Tapia Ladino \\ Universidad Arturo Prat, Iquique, Chile. Email: marcela.tapia@unap.cl \\ Romina Ramos Rodríguez \\ Universidad Arturo Prat, Iquique, Chile. Email: romina.ramos@unap.cl
}

\begin{abstract}
Resumen: La migración fronteriza es un fenómeno que cada día adquiere mayor importancia en el continente en un contexto de crisis de los países del Norte y del fortalecimiento económico de algunos países sudamericanos, como es el caso de Chile. En este sentido, interesa revisar el caso de la migración femenina a la región de Tarapacá en los últimos años, los motivos para migrar, la experiencia del cruce de la frontera y el lugar que ocupan las redes de apoyo en la configuración de la migración fronteriza en el contexto de recepción. El análisis de dicha experiencia migratoria y el accionar de la Pastoral de Migraciones -de acuerdo al relato de las migrantes- permiten indagar sobre cómo se estructura la comunidad en destino, su constitución y seguimiento en una región fronteriza. Las características de las migrantes y de las redes de apoyo permiten explicar el acceso a nichos laborales específicos feminizados, la precariedad de las condiciones de establecimiento y las estrategias de movilidad fronteriza.
\end{abstract}

Palabras clave: Migración fronteriza, transnacionalismo, redes de información, mujeres migrantes.

\section{Female border migrants in Tarapacá in the early $21^{\text {st }}$ century. Border crossings and support networks}

\begin{abstract}
Border migration is an increasingly important phenomenon in the region due to the current crisis context of northern countries and the economic strengthening for some South American nations as is the case of Chile. The focus of this study is female migration to the region of Tarapacá, Chile, over the past few years, the motivations for migrating, the border crossing experience, and the place of support networks in the configuration of border migration in the context of reception. The analysis of that migratory experience and the work of entities that provide pastoral care for migrants based on the testimonies of migrants themselves- allow us to explore how the community is structured at destination, its composition and monitoring in a border zone. The characteristics of migrant women and their support networks help explain their access to specific feminized employment opportunities, the fragility of their living conditions for migrant women, and border mobility strategies.
\end{abstract}

Key words: Migration border, transnationalism, information networks, migrant women. 


\section{Mulheres migrantes de fronteira no Tarapacá ab início do século XXI. Cruzando fronteiras e redes de apoio}

Resumo: A migração de fronteira é um fenômeno que a cada dia se torna mais importante no continente em um contexto de crise de do Norte e de fortalecimento econômico de alguns países sul-americanos como o Chile. Neste sentido, é interessante analisar o caso da migração feminina para a região de Tarapaca, nos últimos anos, as razões para a migração, a experiência de cruzar a fronteira e o lugar das redes de apoio na configuração da migração de fronteira no contexto da recepção. A análise da experiência de migração e as ações da Pastoral da Migração, de acordo com a história do migrante permite indagar sobre como estrutura-se a comunidade de destino, sua constituição e acompanhamento em uma região de fronteira. As características dos migrantes e das redes de apoio ajudam a explicar o acesso a nichos específicos de trabalho feminizados, a precariedade das condições de establelecemento e as estratégias de mobilidade transfronteiras.

Palavras-chave: migração de fronteira, transnacionalismo, redes de informação, mulheres migrantes.

$* * *$

\section{Introducción}

La migración fronteriza es un patrón histórico que, en el último tiempo ha quedado en un segundo plano debido a los rápidos cambios registrados en la movilidad internacional desde la segunda mitad del siglo XX hasta la fecha en América Latina. Luego de auge de la migración de Ultramar a fines del siglo XIX y principios del siglo XX vino el declive de este movimiento a mediados del siglo, para luego adquirir protagonismo la migración a Estados Unidos en las últimas décadas del siglo XX y una aceleración de la migración a España e Italia a fines del siglo pasado y principios de la actual centuria. Hoy la crisis de España ha producido un cambio en el modelo migratorio debido al retorno de latinoamericanos a sus países de origen y la salida de españoles que buscan oportunidades laborales lejos de su país.

Los objetivos de este artículo son indagar en los rasgos de la migración femenina fronteriza estrategias de cruce fronterizo, motivaciones y vínculo con redes de apoyo- que han llegado a Tarapacá y analizar la percepción de las usuarias de la Pastoral Migratoria INCAMI²-Iquique como único dispositivo de acogida de la región. El corpus de material analizado corresponde a los productos de la práctica profesional integrada de Trabajo Social, realizada en la Pastoral de Migraciones de la ciudad de Iquique, en el período Marzo-Diciembre 2011 y a los avances de investigación del material teórico y primeras entradas al campo recabado en el marco del Proyecto Fondecyt de Iniciación sobre migración y movilidad fronteriza. El afán investigativo se centra en indagar en los procesos de vinculación, ya que la migración, dada sus características de movilidad territorial constante, necesita la articulación de las redes sociales que permitan construir funciones de apoyo emocional, informativo e instrumental. Asimismo, se 
adentra en el análisis de la información obtenida de la experiencia migratoria de las propias usuarias, respecto de las expectativas y motivaciones para migrar, la experiencia del cruce de la frontera, la acción de las redes y las oportunidades laborales encontradas en Iquique, entre otros aspectos.

La metodología utilizada corresponde a dos grupos de discusión realizados con mujeres (9) que concurren activamente a la Pastoral. En la constitución del grupo se consideró a mujeres de nacionalidad Boliviana y Peruana, con visa de turismo, temporaria, sujeta a contrato y definitiva. El rango de edad del los grupos iba entre los 20 y los 60 años económicamente activas. Respecto del nivel escolar, la mayoría señaló tener estudios secundarios completos (7 de 9), ser solteras (8 de 9) y tener uno o más hijos (9 de 9). En relación al ingreso a la región por primera vez casi todas lo hicieron por el paso fronterizo Colchane, en calidad de turistas. El perfil de las mujeres escogido, se debe al levantamiento de información de tipo cuantitativo realizado en primera instancia, que de acuerdo a la información sociodemográfica y migratoria de las beneficiarias de la Pastoral. Según esos datos, se constata que del total de personas que atiende la organización el 70\% corresponde a mujeres de origen boliviano, mientras que un $20 \%$ corresponde a mujeres de origen peruano. A su vez, se integran las entrevistas en profundidad realizadas a tres voluntarios de la organización, Director Ejecutivo de la Pastoral y coordinador del proyecto Tres Fronteras.

El trabajo se organiza de la siguiente manera: en una primera parte se identifica el contexto de la migración en Tarapacá como espacio transfronterizo y el lugar de la Pastoral Migratoria como dispositivo receptor de migrantes fronterizos desde los años 90 a la fecha. La segunda parte, revisa los aspectos teóricos utilizados en el análisis, como el enfoque transnacional, la emergencia de circuitos transnacionales y la articulación de redes migratorias en el estudio de la migración fronteriza. En el tercer apartado, y a partir de la información recogida en los grupos de discusión y las entrevistas, se describen los motivos y estrategias para cruzar la frontera de las mujeres usuarias de la Pastoral, el marco jurídico que modela el ingreso de personas, la contigüidad territorial fronteriza y las estrategias de cruce de las mujeres migrantes. Finalmente se analiza la acción de las redes migratorias y la Pastoral como dispositivo de acogida, recogiendo el debate teórico antes expuesto y presentando las conclusiones finales.

\section{El contexto de la migración fronteriza y la acción de la Pastoral Migratoria}

\section{Tarapacá $^{3}$ como escenario para la migración fronteriza}

La región de Tarapacá ha sido escenario de tránsito y movilidades fronterizas desde antiguo, incluso antes de su configuración decimonónica con el establecimiento de los estados nacionales, se registraba un importante movimiento de personas que buscaban complementar las ventajas de 
los distintos pisos ecológicos del espacio andino (Gunderman y González, 2008). Una vez establecidas las fronteras en la primera mitad del siglo, los flujos de personas se estructuraron en torno a los ciclos económicos interrumpidos por el conflicto bélico de la Guerra Pacífico y el impacto de los impulsos nacionalizadores llevados a cabo en dicho espacio durante la posguerra (Norambuena, 2002; Tapia, 2012). Durante el ciclo salitrero el cruce de la frontera no implicó mayor dificultad, más allá de los obstáculos geográficos en el caso de los bolivianos, puesto que en la práctica el control fronterizo no se desplegó en la zona hasta 1927 sumado a una política no declarada explícitamente que promovió de atracción de mano de obra por parte de los dueños de las salitreras (González, J. A., 2008; González, S., 1995, 2009; Tapia, 2013). Sin embargo, en el marco del litigio diplomático por las provincias cautivas, se produjo un proceso de chilenización compulsiva que afectó a la población peruana tarapaqueña que produjo una emigración forzada hacia Perú (González, S., 2004). Con todo, tanto el contexto diplomático adverso como las dificultades geográficas, especialmente para el caso de Bolivia, no fueron motivo suficiente para impedir el tránsito y la circulación de personas de origen fronterizo que buscaron cruzar la frontera, atraídas por el floreciente mercado laboral salitrero (González, S., 1995, 2002, 2009; Tapia, 2013; Tapia y Ovando, 2013).

En relación al escenario geográfico de la histórica región de Tarapacá, los datos señalan que ésta comparte casi $600 \mathrm{Kms}$. de frontera con Bolivia y 167,6 Kms. de frontera con Perú. Los departamentos colindantes son La Paz, Oruro y Potosí en el caso de Bolivia y Tacna en el caso de Perú. Respecto de los primeros, los departamentos bolivianos tienen la particularidad de concentrar casi la mitad de la población del país (4.166.787 Habs.), espacio en el que se incluye a la capital nacional, La Paz y una de las ciudades de mayor crecimiento urbano en las últimas décadas como es El Alto. Dicha población se encuentra repartida en $305.761 \mathrm{kms}^{2}$ frente a sólo 42.225,8 kms² de Tarapacá (Marteles, 2009). Es decir, aunque se trata de un área de alta concentración de población especialmente en la capital altiplánica y en el Alto, disminuye en la medida que se acerca a la zona fronteriza con Chile.

En lo que respecta a la frontera de Tarapacá con Perú, la provincia colindante es el departamento de Tacna con 288.781 habitantes según el censo peruano de 2007, lo que representa el 8,3\% de la población peruana (Berganza y Cerna, 2011). A diferencia de Bolivia, la capital peruana dista de la frontera más de $1800 \mathrm{Kms}$., por tanto se trata de un espacio distinto al anterior. A pesar de lo señalado la mayor parte de la población del departamento de Tacna se concentra en las ciudades con un 91,3\% y en general el departamento ha tenido un crecimiento poblacional sostenido, especialmente la provincia de Tacna desde los años 90 a la fecha. Este crecimiento se explica por la migración proveniente de la sierra y el altiplano, especialmente de Puno y Juliaca hacia la ciudad de Tacna. De este modo la ciudad de Tacna es unas de las provincias de mayor crecimiento del mismo departamento entre 1993 y 2007, pasando de 188.759 habitantes a 262.731 respectivamente (Berganza y Cerna, 2011: 16). 
Por su parte, la población de la actual I Región de Tarapacá según el reciente censo de población 2012, se estimó en 300.021 habitantes distribuidos en una superficie de $42.225,8 \mathrm{kms}^{2}$, que representa el 5,57\% del territorio nacional. En relación a población de origen fronterizo en la región, según las rondas de censos de 1982, 1992 y 2002 se aprecia que la población boliviana y peruana presenta una tendencia a la feminización y un aumento de los años de escolaridad en el periodo intercensal, sin embargo los primeros tienen menos años de escolaridad que los segundos (Tapia, 2012). También se percibe una tendencia al aumento de los extranjeros fronterizos en zonas urbanas de Arica e Iquique (Tapia, 2012). En la revisión de los datos del Censo 2012, publicados recientemente, se aprecia que del total de extranjeros censados en la Región de Tarapacá (22.165 personas) un $77 \%$ son de origen fronterizo, es decir 17.232 personas de los cuales el $48 \%$ corresponde a peruanos, el $36 \%$ es boliviano y un $3 \%$ es argentino (Ine, 2013).

\section{Mapa zona fronteriza de Tarapacá ${ }^{4}$}

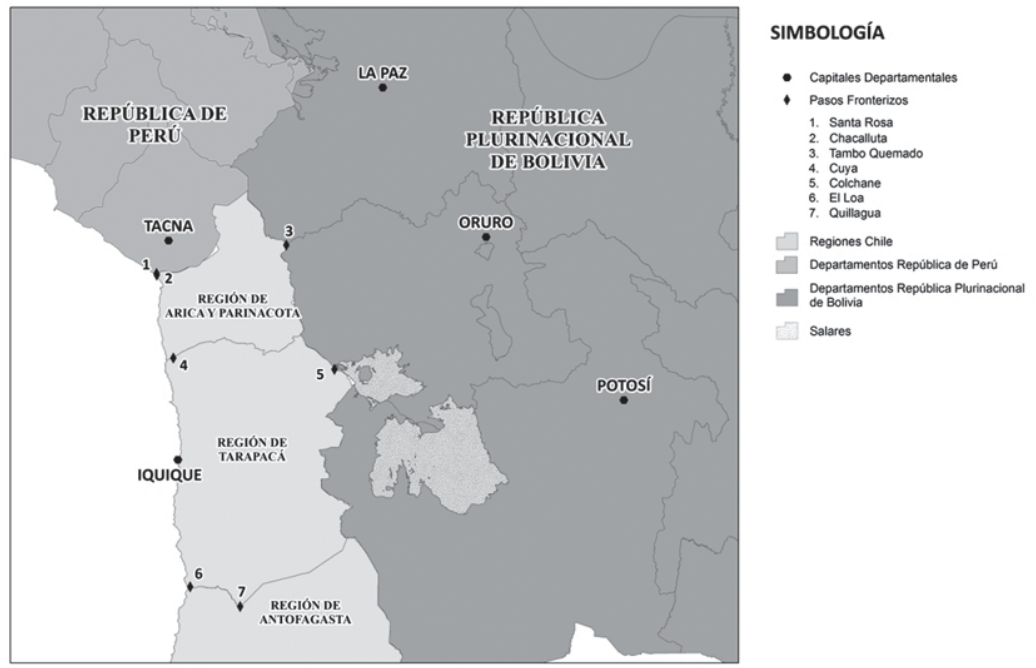

En este contexto es posible afirmar que en el siglo XX y entrado el siglo XXI, la histórica Región de Tarapacá ha sido uno de los principales receptores de trabajadores estacionales de origen fronterizo así como de migrantes en el sentido tradicional de la expresión, que en muchas ocasiones vinieron a probar suerte y luego decidieron quedarse (González, J. A., 2008; González, S., 2009). La cercanía, dada por la contigüidad, los ciclos económicos, el consecuente efecto llamada del mercado laboral, la creciente internacionalización de la región registrada desde los años noventa del siglo XX, las recurrentes crisis de los países vecinos y el bajo nivel de desarrollo de los departamentos fronterizos, han configu- 
rado a Tarapacá como un lugar para concretar proyectos migratorios de corto y largo aliento.

Desde una mirada continental es posible agregar que en las últimas décadas América del Sur ha pasado del boom migratorio de los 90, con destino preferente a Europa y Estados Unidos, al retorno tras la crisis en Europa desde el 2008 y la búsqueda de nuevos destinos migratorios intrarregionales (Texidó y Gurrieri, 2012). Los destinos históricos dentro del continente, Argentina y Venezuela, han mantenido su importancia aumentando la migración, sin embargo se aprecia una diversificación especialmente en la de origen fronterizo (Texidó y Gurrieri, 2012). En este contexto Brasil y Chile se han ido consolidando como países receptores de migración sudamericana dado su desempeño económico, la inserción internacional, el envejecimiento de la población chilena y la baja aceptabilidad de los nacionales por ocupar puestos de trabajo de menor estatus y reconocimiento social (Schmidt-Hebbel, 2006; Solimano, Mellado, Araya, Lahoz y Ocón, 2012).

En este panorama y de acuerdo a los resultados del censo 2012, la población extranjera en Chile asciende a 339.536 personas, de las cuales el primer lugar en importancia lo ocupan los peruanos (30,52\%), seguido por los argentinos (16,79\%), en tercer lugar los colombianos (8,07\%) y en cuarto lugar de importancia los bolivianos $(7,415)$. Si bien se mantiene el predominio sudamericano de manera similar al censo de 2002, se aprecia un desplazamiento de extranjeros de origen argentino por los peruanos a nivel nacional, así como un notable crecimiento en el periodo intercensal de un $45,7 \%$.

\section{La Pastoral Migratoria, el dispositivo receptor de migrantes fronterizos de los 90}

La Pastoral de Migraciones de Iquique es una institución católica dependiente del Obispado de Iquique cuyos antecedentes se encuentran en la Pastoral de Trabajadores de los años 80. El trabajo de la organización fue revitalizado a principios del año 2000 por un grupo de sacerdotes scalabrianos que se propusieron establecer una red de dispositivos de acogida a migrantes en Arica, Iquique, Pisiga, Calama y Copiapó. En total, este trabajo incluyó a seis diócesis del norte de Chile vinculados con las Diócesis de Tacna y Oruro. Su objetivo principal ha sido acompañar pastoralmente a los migrantes desde sus comunidades de origen hasta las sociedades de destino y brindarles apoyo. Desde los años 90 la Pastoral de Migraciones se vinculó al trabajo que ha realizado el Instituto Católico Chileno de Migración INCAMI en el marco del aumento de las migraciones limítrofes a Chile, del número de refugiados y de solicitantes de acogida en Chile. A partir del año 2003 INCAMI ha implementado los Departamentos de Pastoral Migratoria en las distintas diócesis del país promoviendo el trabajo con migrantes o en tránsito y a las personas que las atienden ${ }^{5}$. En este sentido, la Pastoral de Migraciones de Iquique atiende especialmente las primeras necesidades de los recién llegados, como alojamiento 
en casos de apremio, orientación laboral y jurídica, en la medida que cuentan con voluntarios; y acompañamiento espiritual a cargo de religiosas y sacerdotes.

En los últimos años, el trabajo de la Pastoral de Migraciones de Iquique se ha articulado con mesas técnicas de trabajo sectorial de organismos públicos regionales, esta vinculación tiene por objetivo contar con el apoyo de las entidades públicas en el tratamiento de algunos casos. Este vínculo no está exento de tensiones debido a la baja aplicación del Convenio Internacional de los Trabajadores Migrantes y sus Familias, que fue ratificado por el Estado chileno el año 2005. En efecto, si bien la Pastoral desde sus inicios ha recibido ayuda de organismos gubernamentales, no están amparadas por los compromisos internacionales en materia de garantizar derechos de los migrantes, sino que se trata de iniciativas voluntarias de los encargados de los servicios públicos que se vinculan con ella. En general la coordinación con las reparticiones públicas es coyuntural y limitada a los casos de difícil solución.

De acuerdo a la información recabada en los registros de ingreso que mantiene la Pastoral de Iquique, se estima que la población de mujeres migrantes que atendió durante el año 2012 fue de 900 personas, en su mayoría bolivianos y peruanos, seguido de ecuatorianas y colombianas en menor cuantía. En una estimación total desde los años 90 se puede indicar que hasta el año 2012 atendió a un número aproximado de 19.600 personas, entre mujeres y hombres. En su corta historia la Pastoral de Migraciones iquiqueña ha asistido a la población extranjera en aspectos como procesos de normalización, como fue el caso de la regularización migratoria del año 2007- 2008. Durante este proceso se otorgó visa de residencia temporaria a más de 50.000 extranjeros que no contaban con sus papeles al día (Stefoni, 2011). En Iquique se estima que cerca de cinco mil personas se acogieron a este beneficio. ${ }^{6}$ Además, la Pastoral contribuye con la descentralización del sistema de refugio, participa en encuentros nacionales que se realizan tanto en Chile como en Bolivia y Perú, y promueve las celebraciones de las fiestas patronales contribuyendo a forjar vínculos basados en valores nacionales y el diálogo con la sociedad receptora.

Desde una mirada nacional en los últimos años se registra un aumento del trabajo de los dispositivos de acogida de inmigrantes al amparo de la Iglesia Católica en las principales ciudades de Chile. Ello porque la migración fronteriza, especialmente de origen peruano, ha ampliado sus destinos migratorios y ha puesto a Santiago como uno de los lugares de establecimiento preferente. Estudios que cubren este fenómeno en la capital advierten de la precariedad en la que viven los recién llegados, la incorporación laboral en la economía informal y las dificultades para integrarse socialmente (Jensen, M., 2009; Stefoni, 2009; Tijoux, 2002). De manera similar a lo que ocurre en Tarapacá la Iglesia ocupa un papel fundamental como dispositivo de acogida (Jensen, F., 2013), junto a ONGs y departamentos de universidades que prestan atención y apoyo a los migrantes sudamericanos en general. 


\section{Transnacionalismo, frontera y redes en el estudio de la migración fronteriza}

Cuando nos referimos a las migraciones fronterizas y transfronterizas en América Latina, aludimos a un fenómeno reciente en términos históricos, puesto que las definiciones geográficas de las delimitaciones fueron realizadas en las primeras décadas del siglo XIX. A partir de la consolidación de las nuevas repúblicas el conteo de personas a través de los censos fue una tarea central en el afán de delimitar a las nuevas naciones y su población. En este sentido, la definición utilizada para contar extranjeros hace alusión al cambio de residencia de las personas de un estado-nación a otro, distinto al de nacimiento. En esta definición primó el nacionalismometodológico, es decir, la idea de la sociedad nacional como contenedor, donde los contornos de la sociedad coinciden con los del estado-nación (Llopis, 2007: 103). Este es el sustrato epistemológico que subyace en las definiciones de fronteras y de la movilidad humana que en gran parte hemos heredado a través de los estudios migratorios (Wimmer y Schiller, 2003).

La teoría migratoria transnacional es un marco que permite superar el sesgo del nacionalismo metodológico y es un paradigma adecuado para el estudio de la movilidad fronteriza porque atiende a un amplio registro de exploración del movimiento humano (Marcu, 2013: 121) y a la diversidad de relaciones sociales e implicaciones de quienes atraviesan las fronteras. En el centro del enfoque se encuentran nociones como frontera, lugar, redes e interrelaciones que caracterizan a los espacios sociales transnacionales, entendido como una concatenación de relaciones transfronterizas y de prácticas sociales por sobre las fronteras, como las familias transnacionales y las organizaciones de migrantes, entre otras configuraciones (Faist, 2000, 2012). Esos vínculos son todavía más perceptibles en una región fronteriza, como ocurre con el caso de Tarapacá, la que se entiende como un espacio que traspasa las líneas de separación y origina una integración entre los territorios colindantes (Morales, 2010: 187). Dicha integración no sólo se refiere a los lazos económicos, sino también a la circulación de personas, la movilidad de las mismas y el establecimiento de migrantes, dando lugar a relaciones sociales desde abajo, como lazos formales e informales, más o menos densos y continuos en el tiempo.

En el contexto de las migraciones fronterizas el enfoque trasnacional aporta conceptos que permiten captar fenómenos desterritorializados, como los flujos de población que cruzan los lindes, los fenómenos territorializados y los dispositivos de control de dichos flujos de acuerdo a criterios de pertenencia nacional (Faist, 2012). Según Faist (2012) la noción de espacio social transnacional se refiere así a la serie de relaciones transfronterizas y prácticas sociales por sobre y a través de las fronteras que incluye tanto a los flujos como a los lugares o territorios. Por tanto los estados ya no son vistos como compartimentos estancos dados de manera cuasi natural en el análisis social, donde la sociedad termina con el límite. Lo que se registra 
es que esta noción es a menudo superada o desbordada por los flujos migratorios y las prácticas sociales de las personas que viven en la frontera, la cruzan permanentemente y la convierten en un recurso y en una oportunidad (Faist, 2012; Sinatti, 2008).

Distintos estudios que vinculan la transnacionalidad con el desarrollo han incorporado el retorno como parte consustancial de la migración, en la medida que éste se convierte en un medio para promover cambios en los lugares de origen o concretar los objetivos de la movilidad (Cortes, Genevieve, 2000; Cortes, Geneviève, 2004; De La Torre, 2004; Sinatti, 2010). Los compromisos asumidos antes de partir, los acuerdos tomados con los que se quedaron o las crisis económicas, ha convertido el retorno en una estrategia que permite concretar lo propuesto o hacer frente a los malos tiempos (Marcu, 2013). Por tanto, la visión que predominó por largo tiempo del retorno como el fin del ciclo migratorio se entiende hoy como parte del mismo y como una aspiración que da vida a prácticas sociales de movilidad que configuran los campos sociales transnacionales.

El aporte de la acción de las redes migratorias en el marco del transnacionalismo posee una elevada capacidad explicativa para comprender, por ejemplo, la selectividad por sexo de quienes migran (Menjívar, 2000) y la continuidad de las migraciones en el tiempo más allá de las causas que la iniciaron (Massey, Alarcón, Durand y González, 1991). Al situarse en un camino intermedio entre las explicaciones centradas en el individuo y aquellas que se sitúan en las estructuras, reconoce la agencia de quienes deciden partir sin desatender los factores estructurales que la motivan. De esta forma se entiende que los procesos históricos o los contextos globales pueden condicionar la acción de los individuos, pero no necesariamente las determinan. Al mismo tiempo, se reconoce que la decisión de migrar no es siempre una decisión individual, sino que es fruto de la acción de un conjunto de relaciones sociales en las que están inmersos los migrantes, que en muchos casos se mantienen más allá del hecho de partir, configurando así un nuevo espacio. De modo que el lugar que las personas ocupan en las microestructuras sociales, como la familia, los amigos o el entorno cercano facilita la comprensión de las decisiones concretas de los actores.

En este sentido, las redes migratorias tienen la particularidad de unir a personas situadas en distintos puntos geográficos y sociales, permitiendo comprender la movilización de los flujos, los procesos de integración y el impacto de los inmigrados en la estructura social del país de recepción (Aparicio y Tornos, 2005). Numerosos estudios han demostrado la importancia de las redes en la configuración de cadenas migratorias y en la perpetuación de las migraciones más allá de los factores que le dieron lugar (Durand, 2000; Gurak y Caces, 1998; Massey, et al., 1991). Por tanto, atender a la red de relaciones en las que estaban inscritos los migrantes antes de partir o aquellas que crean durante el cruce fronterizo o durante la llegada, son centrales para comprender por qué se animan a migrar, cómo se elabora el viaje, el cruce la frontera, la forma en que se concreta la migración y los modos de incorporación social y laboral en la sociedad de destino. 


\section{La migración fronteriza femenina a Tarapacá y las redes de apoyo}

\section{Los motivos para cruzar la frontera}

Los informes sobre migraciones no forzadas señalan que las personas que deciden ir a otro país regularmente poseen motivos económicos para migrar (Crossette, 2011; Oea, 2012; Pnud, 2009). La búsqueda de mejores expectativas salariales y las mayores oportunidades de empleo fuera de las fronteras nacionales son los principales incentivos que esgrimen los migrantes para salir de sus países. Normalmente esta decisión se enmarca en un contexto de bajas expectativas de mejora económica en el corto plazo, de crisis políticas y económicas que impulsan a buscar nuevas alternativas más allá de las fronteras. En América Latina se estima que los migrantes intrarregionales ascienden a más de dos millones de personas, como producto de los procesos de integración económica regional, las restricciones de ingreso impuestas por los países desarrollados y de la existencia de una historia compartida de relaciones económicas y sociales, entre otros factores (Nicolao, 2011).

Los sistemas migratorios predominantes del siglo XX fueron el del Cono Sur, que tuvo como principal destino Argentina y el de los países andinos, que ubicó a Venezuela como receptor histórico. En este marco países como Perú y Bolivia han mantenido un claro perfil emigratorio alcanzando fuerte presencia en Argentina y Brasil en las últimas décadas del siglo XX (Nicolao, 2011). En años recientes se han diversificado los destinos migratorios en un contexto de crisis económica de los países del norte; y en el caso de los países fronterizos, se identifica un aumento de bolivianos en Argentina, Colombia y Venezuela y de peruanos en Chile y Argentina (Texidó y Gurrieri, 2012) ${ }^{7}$.

En el caso de estudio, de mujeres migrantes que han llegado a Tarapacá y que participaron del grupo de discusión, se advierte la motivación económica como central para cruzar la frontera con un proyecto migratorios más o menos definido. Este plan corresponde a las metas u objetivos a alcanzar, estrategias para llegar a destino y un tiempo estimado para cumplir esos fines. De manera coherente con los informes de migración, en el caso estudiado, la motivación económica explica de manera general la llegada a Chile y a la región en específico, de la mayoría de las personas provenientes de Perú y Bolivia. Tal como lo señalan algunas de las mujeres:

“...vine acá porque quería más ingresos y así progresar más, o sea como en mi país el sueldo es muy poco y vine acá a conocer y para que me vaya mejor acá y tener un futuro mejor no solo a mí ahora, ahora pienso más con mi hija, porque tengo una hija, aquí se gana más en comparación a mi país”. (Mujer boliviana, visa temporaria, 27 años) 
“...se decía que había mejores perspectivas de trabajo, para sacar adelante,a nuestras familias”. (Mujer boliviana, 50 años, residencia definitiva)

Esta situación se relaciona con las diferencias de desarrollo a uno y otro lado de la frontera, así como el acceso de salarios más altos respecto de los que optan en Bolivia o Perú por tareas u oficios similares. Los factores que explican este diferencial radican las brechas de desarrollo existentes en la zona fronteriza y a los mayores indicadores de pobreza de los países limítrofes, especialmente de los departamentos vecinos de Tarapacá. En el caso de Bolivia para el año 2001 los Indicadores de Desarrollo Humano IDH de los departamentos contiguos a la región en estudio eran los siguientes: La Paz 0,631, Oruro, 0,618 y Potosí 0,641 (Arauco, V., 2009: 10-11). En el caso de Perú los indicadores para el año 2002 fueron los siguientes: Puno 0,542 y Tacna con 0,687 (Pnud, 2005: 268-269). La Región de Tarapacá contaba con un IDH de 0,775 el año 2003, lo que muestra un mejoramiento del indicador desde el año 2009 en ámbitos como cobertura de salud, educación e ingreso (Pnud, 2006: 14). Por lo tanto traspasar la frontera implica obtener mayor rendimiento de los recursos que se podrían obtener en el lugar de origen, en oficios similares o de menor calificación, e incluso en aquellos de mayor cualificación (Solimano, et al., 2012).

Sin embargo, es preciso señalar que en el análisis los motivos económicos no son la única razón que impulsa a la salida del país, aparecen motivos extra económicos como la baja responsabilidad paternal en el sostenimiento de la familia y violencia contra de la mujer entre otros. Tal como señalan las informantes del grupo de discusión:

"Yo me he venido por el motivo que yo tengo hijos allá en Bolivia, que se han quedado con el papá de mis hijos que yo tengo niños allá en Bolivia (sic), mi última hija tiene 13 años, y por eso yo me he venido aquí y porque yo con ese problema que yo tenía me sentía mal yo soy de Cochabamba, yo me sentía mal, mal, mal, por eso yo me he venido a este lado, yo estaba de la mente mal, él me trataba mal, me he venido de ahí me quedé aquí trabajando, de ahí ahorita yo no vivo con el papá de mis hijos, yo soy pa mis hijos padre y madre, porque yo tengo que trabajar para mis hijos, para sacar adelante para hacerles estudiar a mis hijos, ahora estoy aquí por mis hijos”. ( Mujer boliviana, 40 años, visa turismo).

"uno piensa yo vine porque tuve problemas con mi esposo, llega un momento que no puedes más, tomé la decisión de dejar a mi esposo, me trataba muy mal, yo era la base económica, porque yo quería tener la plata para mañana, no sabía si mi esposo me traía para mañana para comer. Siempre pensaba en mañana, pensando en mi esposo, mis hijos, en todo, si mis hijos querían comerse una fruta también, mama cómprame, y si le pedían al papá les decía no”. (Mujer peruana, 55 años, visa residencia definitiva) 
Estudios migratorios en América Latina advierten de las motivaciones extraeconómicas de la movilidad femenina, ya que al tratarse de flujos feminizados es posible plantear que el desplazamiento alberga la posibilidad de cambiar o al menos alterar las relaciones de género respecto de la situación de partida. La motivación laboral, la asunción explícita de la provisión económica de parte de las mujeres y el paso de una estructura de género a otra, son algunas de las razones que explican esta posibilidad (Ariza, 2000; Camacho y Hernández, 2005; Rivas, Gonzálvez, Medina, Rodríguez, Tapia, González et al., 2008). Aunque los resultados del proceso migratorio no ocurren siempre en una dirección, sí se reconoce la eventualidad de que estos sucedan o que las mujeres experimenten mayor autonomía o piensen en formas distintas de relacionarse con nuevas parejas (Gonzálvez y Tapia, 2013; Poggio, 2000). En otro sentido, algunas investigaciones han detectado que el contexto migratorio puede dar lugar a procesos de reafirmación de la masculinidad del migrante o no migrante, en la medida que la movilidad se convierte en una forma de cumplir con el mandato de provisión económica o de administrar dichos recursos sin con ello alterar la autoridad patriarcal (Pingol, 2001, 2004; Rosas, 2008; Tapia, 2010) ${ }^{8}$.

En el caso estudiado es necesario tener en cuenta las características de Bolivia como sociedad emisora, donde se advierte que desde el discurso político la violencia en contra de la mujer es vista como algo indeseado y se ha avanzado en políticas públicas por erradicarla, no obstante, es una realidad que no se ha logrado eliminar (Arauco, E., Mamani y Rojas, 2007; Crespo, 2005; Guaygua y Castillo, 2008). En general, lo que se aprecia es que la violencia en sus distintas manifestaciones es una práctica habitual en las relaciones de pareja y se encuentra naturalizada como un modo común de interacción. Las familias y los entornos sociales donde existe violencia intrafamiliar tienden a justificarla, encubrirla o invisibilizarla, dejando en muchos casos a las mujeres víctimas en el mayor desamparo (Tapia, 2011). Por tanto la migración se constituye en una alternativa para dejar atrás la violencia y un matrimonio o convivencia mal avenida. La contigüidad fronteriza favorece la decisión de cruzar el límite debido a los menores costos del traslado y a la posibilidad de contar con información o redes que faciliten el cruce, a diferencia de la migración de larga distancia que requiere de mayores recursos económicos y humanos.

\section{Marco jurídico, contigüidad fronteriza y estrategias de cruce}

De acuerdo a la información obtenida en entrevistas a informantes claves sobre el origen de la población boliviana y peruana, se señala que ésta proviene preferentemente de los departamentos vecinos de la región, es decir, Tacna en el caso de Perú; La Paz, Oruro y Potosí en el caso de Bolivia. La cercanía con el lugar de origen, la disponibilidad de transporte en autobuses y la mayor conectividad desarrollada dentro de los países fronterizos ha facilitado la configuración de proyectos migratorios de corto plazo.

Una vez instaladas en Iquique y conocido el destino migratorio, la proximidad del paso fronterizo de Colchane -ubicado a 266,5 Kms. de 
Iquique-, permite lo que las informantes denominan hacer frontera, es decir que una vez vencidos los 90 días de la visa de turista vuelven a Bolivia, permanecen algunos días allí y luego regresan a Iquique activando con el cruce otros nuevos 90 días. La visa no les habilita para trabajar, pero normalmente lo hacen en la economía sumergida. Sin embargo, cuando las migrantes solicitan visa temporaria o sujeta a contrato, que les permite mayor tiempo de permanencia, existen prórrogas que se les brinda por parte del Departamento de Extranjería y Migración mientras logran contar con una visa más duradera:

"Yo esperaba tener mis papeles, como cuando uno no tiene papeles, no puede trabajar fácil, tiene que salir de 90 días y de vuelta a ingresar, eso no era fácil para mí”. (Mujer boliviana, 27 años, visa temporaria)

"Sí, cuando estaba trabajando, cuando no tenía papeles, yo ingresaba y tenía que salir, eso costaba, a veces no te dejaban, porque te preguntan ¿cuánta plata llevas?, todo te preguntaban, y yo tenía que hacer mis papeles, pasaporte”. (Mujer peruana, 55 años, Residencia definitiva)

Desde el año 2009 está vigente el Acuerdo de Residencia de los Nacionales de los Estados Partes del MERCOSUR Bolivia y Chile, por el cual los nacionales de Argentina, Bolivia, Brasil, Paraguay y Uruguay pueden acceder a visaciones de residencia temporaria por un año prorrogable por igual periodo sin la necesidad de contar con un contrato de trabajo al momento de la solicitud. Sin embargo, de acuerdo a la información obtenida de informantes claves, la población boliviana se acoge lentamente a este beneficio por desconocimiento, por el valor del trámite. Por lo tanto prefieren seguir entrando como turistas por Colchane, trabajar tres meses hacer frontera y volver a entrar por otros 90 días. En el caso de la población peruana que llega a la Tarapacá, ésta lo hace en su mayoría por el paso fronterizo de Chacalluta y debe contar con pasaporte a la hora de cruzar e informar que su destino es una región distinta a la XV Región de AricaParinacota que es fronteriza a Perú. Sin embargo, los peruanos que ingresan a Arica y que sólo quieren permanecer allí se acogen al Convenio de Tránsito de Personas en la Zona Fronteriza chileno-peruana de Arica y Tacna, firmado en 1983 y al Acuerdo para el Ingreso y Tránsito de Nacionales Peruanos y Chilenos en Calidad de Turistas con Documento de Identidad de $2005^{9}$. El convenio les permite ingresar por siete días con documento de identificación, los que se pueden volver a usar una vez que regresan a Tacna, activando así un sistema de entradas y salidas que explican un fuerte tránsito fronterizo ${ }^{10}$. Así lo señala una de las mujeres del grupo de discusión:

“... agarré que no había nadie, dije ahora es cuando agarré mi mochila, me fui, me fui, preguntando en el camino ¿Qué bus tomo para llegar hasta Tacna? me dijeron- ahí está Cruz del Sur, ahí están los buses, hay varias agencias-, la cosa era que yo tenía que llegar a Tacna. Llegué a Tacna y en Tacna pude ingresar a Chile, preguntan- 
do ahí también, yo súper preguntona,-¿Cómo hago para llegar a Chile?- entonces ahí los tacneños te informan, si puedes entrar a los siete días, bueno esos siete días me quedo no más pues, pero yo no sabía, si ya estoy acá tengo que seguir no más por mi familia. En Tacna ingresé, me dieron siete días, con mi credencial de tres copias, yo no llevé pasaporte, porque no sabía que pedían pasaporte, yo no sabía realmente, porque si hubiera sabido hace tiempo hubiera sacado pasaporte. Me quedé en Arica dos días, en un apartamento con unos peruanos, me dice el sitio más cercano que uno puede llegar acá es Iquique porque Santiago está más lejos y ahí controlan ya ahí, como ya estoy acá siete días, me quedo, no sé que hago. Me voy en camión, no sé. pero yo llego a Iquique, ahí agarré... hablé con un bus, -voy a Iquique le digo, cuánto me cobra-, me dijo ya, le cobro tanto y yo lo dejo en Iquique, pero va a pasar un control público, porque siete días que le dieron es hasta Arica, no hasta Iquique-, yo dije -no importa-, si me botan me botan, ya estoy acá, llegué al paso de Cuya, llegué a Iquique, no conocía a nadie”. (Mujer peruana, 41 años, visa sujeta a contrato)

En los casos revisados, se aprecia que la migración puede ir por etapas, especialmente en el caso peruano debido a la existencia de reglamentos jurídicos específicos para el ingreso por el acceso norte, Chacalluta. Llegar a Arica primero, luego pasar como sea en algunos casos, para instalarse en Iquique y pensar en seguir más al sur si es posible. De modo que la trayectoria migratoria de las mujeres peruanas del grupo de discusión, se construye en el camino de acuerdo a la información que obtienen en su tránsito y los aprendizajes que adquieren en el proceso. El proyecto migratorio se modifica de acuerdo a las circunstancias, a las oportunidades encontradas y a las posibilidades que otorga el marco jurídico y el mercado laboral. Así lo señaló otra de las mujeres del grupo:

"cuando no tenía papeles, yo ingresaba y tenía que salir, eso costaba, a veces no te dejaban, porque te preguntan cuánta plata llevas-, todo te preguntaban, y yo tenía que hacer mis papeles, pasaporte. Si tenía pasaporte sí me dejaban, cuando todavía no tenía pasaporte no me dejaban entrar. Hasta ahora no dejan entrar a algunos, porque mi hermano ha venido aquí conmigo y no lo han dejado entrar, el tiene carnet peruano, está haciendo los papeles aquí, incluso cuando tienen carnet chileno te exigen más, cuando tienes puedes trabajar fácil”. (Mujer peruana, 55 años, Residencia definitiva)

Luego de la extensiones de las visas de turistas y el acceso a visa sujeta a contrato, algunas mujeres comienzan a hacer traer a sus parientes, amigos o cercanos. Como señaló una de las mujeres del grupo: no, no ha venido, si yo espero conseguir trabajo, si yo veo que hay, si yo veo que hay para mi esposo ya le digo que se venga no mas (Mujer boliviana, 46 años, visa de turismo). La obtención de papeles, las oportunidades laborales y la llegada de familiares permite pensar en planes de residencia de mayor tiempo, los que combinan con regresos periódicos a las comunida- 
des de origen. La posibilidad de retornar, dada la cercanía de la frontera, es un recurso que está presente todo el tiempo configurando idas y vueltas frecuentes, como señala el relato:

"O sea yo pensé que, no sé, tal vez no iba a encontrar trabajo o mal trato con la chilena, pero no sé, pero no, todo lo contrario, me ha ido bien, y ahora he ido a Bolivia, ahora estoy volviendo de vuelta de seis meses que ya estoy acá y ahora estoy tramitando mi papel”. (Mujer boliviana, 40 años, visa turismo).

Lo que se aprecia en este caso es que las estrategias de ingreso de las mujeres que llegan a la región desde Bolivia y Perú están modeladas, por el marco jurídico sobre ingreso y extranjería por las oportunidades laborales que encuentran para ellas y por las facilidades que otorga la cercanía de la frontera. La contigüidad con ambos países permite que independiente del conocimiento que se tenga del país, de los requisitos de ingreso y de la suerte que puedan correr, el expediente del retorno sea parte del mismo proyecto. Por tanto, se trata de un proyecto migratorio que, en muchos casos, no está del todo configurado y que se estructura en la medida que se avanza en el plan. Cada nuevo cruce se constituye en un recurso que se acumula y que sirve de aprendizaje para nuevos proyectos, así las decisiones son rápidas y la duración de la estancia puede ser variable estructurando una movilidad continua.

Algunos estudios que se abocan a la migración peruana en Santiago señalan que la experiencia de los migrantes está más marcada por las huellas de la frontera, es decir, por la condición de extranjero sudamericano, en particular peruano (Jensen, F., 2013). En este sentido es posible postular que si bien en ambos casos se trata de migración fronteriza, no es menos cierto que la distancia entre los lugares de origen de la mayoría de lo/as peruano/as que llegan al centro del país es sustantivamente mayor (superior a $2000 \mathrm{kms}$ ) que aquella que recorren peruanos y bolivianos que llegan a Tarapacá. Por tanto, quienes se dirigen a Santiago desde Perú, se comportan de alguna manera como migrantes internacionales, puesto que la posibilidad del regreso es más compleja, más cara y requiere de más tiempo. Por tanto, la movilidad fronteriza que ocurre en Tarapacá tiene la ventaja de la contigüidad y aunque comparte patrones similares de incorporación laboral y de precariedad social; la posibilidad del regreso, de ir y venir o de establecer un modo de vida binacional, es mayor en la región de frontera que aquella que tiene por destino el centro del país.

\section{Las redes migratorias y Pastoral de Migraciones como dispositivo de acogida}

La acción de las redes es central para comprender cómo se estructuran las migraciones porque son consideradas formas de capital social en tanto son un recurso que portan los migrantes y lo despliegan durante todo el proceso migratorio, es decir, antes de migrar, durante la migración, en el establecimiento y en el retorno. Como se ha señalado la acción de las redes 
explican la magnitud de los flujos, la autosostenibilidad en el tiempo de la migración y la selectividad geográfica y de género de quienes migran, potenciando con ello los lazos que se construyen y las posibilidades de acción de los migrantes (Aparicio y Tornos, 2005; Massey, et al., 1991). En este sentido se entiende como redes de solidaridad y de intercambio que se tejen en un espacio cada vez más global (Payá, 2007: 44). Éstas se constituyen en una de las consecuencias más visibles de la migración transnacional, pues la constitución, generación y el fortalecimiento de las redes migratorias contribuyen a la reproducción de las propias comunidades de origen en las sociedades de destino (Massey, et al., 1991).

En cuanto a sus funciones, se estima que el apoyo es una de las más relevantes, puesto que se consideran agentes de resguardo que generan factores protectores en todo el proceso migratorio. Estos factores son, entre otros, conocimiento de derechos laborales -al amparo de tratados internacionales-, protocolos en cuanto a normalización de antecedentes, comunicación de experiencias migratorias y redes informales de soporte, acompañamiento entre inmigrantes en tránsito y orientación de lugares de asentamiento. Estos elementos permiten la construcción de canales de ayuda que favorecen la movilidad social de los sujetos, pues la vinculación permanente con las redes tienden a amortiguar el peso que tienen sobre los migrantes los costes y la ruptura vital que supone la migración (Gurak y Caces, 1998: 79).

Antes de tomar la decisión de salir, los migrantes regularmente estiman el tiempo de la migración, la duración de la estancia tiene que ver con las oportunidades laborales, el marco jurídico sobre extranjería y la lejanía o cercanía con el país de destino. En el caso de la migración fronteriza, la contigüidad favorece la elaboración de planes de corto plazo que no se corresponden necesariamente con un proyecto de migración, entendido como establecimiento definitivo. Una vez obtenidos los papeles es posible proyectar más tiempo, repensar el plan original o establecer las venidas a Chile como un recurso al que echar mano cuando las necesidades arrecian. En este sentido la contigüidad y las facilidades para viajar favorecen las visitas al lugar de origen y la circularidad de la población, especialmente notoria en el caso boliviano dada la geografía y la puesta en vigor del Acuerdo de Residencia de los Nacionales de los Estados Partes del MERCOSUR el año 2009.

En este escenario la Pastoral Migratoria se constituye en un dispositivo de acogida que cubre las primera necesidades de las recién llegadas, en especial de orientación, información y alojamiento. Particularmente notorio cuando quienes deciden venir a la región sólo traen información y poco apoyo de otros inmigrados:

"Uno cuando llega, no conoce a nadie, llegamos a un sitio y no tenemos donde estar siquiera, venimos, acá (Pastoral) encontramos trabajo y hay un sitio donde estar en una noche, si no estaríamos en la calle, porque si tú te vas a Santiago duermes en la calle, yo he tenido 
amigas que han pasado para allá y no querían ni dormir, estaban durmiendo en la calle hasta que conozcan, porque allá en Santiago, todavía no existe esto". (Mujer de nacionalidad peruana, 40 años, residencia definitiva)

Como señalamos más arriba la migración se constituye para algunas mujeres en una oportunidad para obtener mayor bienestar para la familia y, en ocasiones, para poner fin a la violencia machista. El diferencial de salarios a uno y otro lado de la frontera, permite concretar proyectos como la instalación de un negocio, el pago de deudas o la construcción de la casa. Sin embargo, los motivos no son suficientes para tomar la decisión de partir. Varias mujeres del grupo de discusión declararon haber obtenido ayuda para llegar, especialmente de otras mujeres o de haberse informado sobre las oportunidades y de las ventajas de venir a Iquique previo a la partida.

"Yo tenía ocho hermanos y como mi papá estaba enfermo, quise venir, no conocía tampoco, mi prima me llamaba, aquí hay trabajo, se gana más plata, en Bolivia no se gana así”. (Mujer boliviana, 27 años, visa temporaria)

“yo me voy a Chile, porque yo escuché comentarios. Una cosa es escuchar y otra es vivirlo tú. Escuché comentarios que en Chile había trabajo, pero no sabía qué documentos tenía que traer, no sabía. Entonces no importa, me voy no más, para venir acá yo engañé a mis padres, a toda mi familia, porque siempre preguntan, a los amigos, a las amigas, todos te preguntan. Me voy a Chile porque tengo a mis amigos de promoción que terminamos secundaria que están en Chile, que ya me tienen trabajo, tengo donde llegar, pero todo era mentira, era para mentirles a mis papas, pa que no se preocupen por mí porque yo soy la mayor, regalona de mis padres, los engañé, era la única manera”. (Mujer peruana, 41 años, visa sujeta a contrato).

Quienes no cuentan con redes que los acojan en el primer momento acuden a la Pastoral, porque se informan que allí pueden obtener ayuda. En general, la Pastoral de Migraciones de Iquique atiende a las usuarias en virtud de las necesidades básicas que se presentan en la llegada. Las mujeres que acuden allí saben o se informan en el camino de su existencia, por tanto se refuerza la percepción de apoyo y de dispositivo de acogida. Esta percepción la mantienen tanto las personas que trabajan en la Pastoral como los inmigrantes beneficiarios que llegan a ese lugar. De modo que el vacío que a menudo ocasiona la inmigración y las dificultades que significa enfrentarse a una sociedad distinta y a una cultura diferente queda plasmada en el siguiente relato:

"Yo cuando llegué a Iquique, dije señor si tú me has hecho llegar hasta Iquique acá me quedo ahora qué hago. Dónde voy, entonces yo dije no conozco a nadie, me voy a cualquier iglesia. No conocía la pastoral, no conocía, pase a la feria y preguntando, ahí en una 
iglesia por acá, parece que, yo recién llego, no conozco a nadie, entonces me dijo acá hay una pastoral, acá hay una pastoral, de migrantes peruanos, colombianos. Llamé acá y me quedé a dormir día y noche”. (Mujer peruana, 41 años, visa sujeta a contrato)

Además del apoyo en el primer momento, la Pastoral es una verdadera agencia de empleo, puesto que quienes llegan deben inscribirse y esperar a la/os empleadora/es que vienen a entrevistarlas y llevárselas, a su casa o trabajo, una vez llegado a un acuerdo. Si bien la Pastoral acoge a hombres y mujeres, son fundamentalmente las mujeres extranjeras las que se inscriben y se quedan a esperar a que las llamen mientras conversan, miran televisión o rezan, cuando vienen las religiosas que regularmente las asisten. Los varones acuden, pero prefieren esperar en la calle junto a otros hombres. Por tanto, la llegada a la Pastoral tiene como motivo central la búsqueda de empleo, quienes saben de antemano van directo y quienes no la conocen son orientados en el camino para llegar hasta allí:

"Yo he llegado y como es la casa pastoral, llegué allí a la vuelta y le dije a la encargada, señora, ahí a la vueltita hay una oficina y ahí van las empleadoras y ahí te van a mandar”. (Mujer boliviana, 46 años, visa de turismo).

“Cuando llegué, yo estuve cuatro días durmiendo acá en la pastoral, yo dije tengo que trabajar ya, ya, es la necesidad misma, para tener dinero, para uno comer este, llegué de Perú. Estuve tres, cuatro, cinco días estuve acá, alcancé a comprar un periódico no, yo ya estaba lista, y ahí decía, para limpiar autos, marqué con plumón, me fui, un mes un mes estuve trabajando, limpiando autos en la calle”. (Mujer peruana, 55 años, residencia definitiva).

La mayoría de las mujeres migrantes que acuden a la bolsa de trabajo sabe que las mayores posibilidades están en el servicio doméstico. De acuerdo al perfil sociodemográfico, la mayoría están en edad productiva y reproductiva y aunque muchas de ellas declaren no haber realizado este tipo de oficios antes de venir, saben que es el ámbito donde tienen más oportunidades. La posibilidad de emplearse puertas adentro es una alternativa porque permite ahorrar los gastos de alojamiento y comida. Una vez que tienen mayor conocimiento y obtienen los papeles, dejar el trabajo puertas adentro para pasar al trabajo puertas afuera es una alternativa que les da más autonomía y capacidad de movimiento.

"Yo cuando llegué entré a trabajar cama adentro, cuidando a una niña, cosa que mis patrones mis jefes con quien trabajaba, los fines de semana, los domingos, me daban permiso, pero me decían que me tenía que cuidar harto porque me iban a robar el dinero,, casi no me dejaban conocer nada del lugar, así otros lugares para salir, me atemorizaban, prácticamente para que no salga y no sepa más, tal vez, el valor del dinero, no me explicaban mucho del valor, una amiga vino y ella me explicó, eso vale así, esta moneda boliviana 
vale así, me explicaba, a la playa también, ella me llevó, porque mis jefes no, ella me llevó a la playa por primera vez, todo, esa mi amiga”. (Mujer boliviana, 30 años, visa temporaria).

“Acá mismo (Pastoral), ya llegó el mes, págueme lo que me debe y ahí no más, y fui una entrevista de trabajo, hasta que conseguí trabajo cama afuera”. (Mujer peruana, 55 años, residencia definitiva).

Una vez obtenido un trabajo las migrantes regresan con frecuencia a la Pastoral porque allí encuentran a otros connacionales y pueden realizar distintas actividades. En este sentido se destacan cuestiones de ámbito cultural, asociadas a su prestación de servicios religiosos o la práctica de valores propios de la comunidad de origen. Estos son elementos significativos que portan los migrantes y que forman parte de su vida encuentran eco en la organización de fiestas patronales y religiosas. Por lo que el expediente del regreso a la Pastoral los días de descanso o cuando no les ha ido bien en un trabajo, es un recurso que se mantiene más allá del soporte que entrega en la llegada. Lo anterior se grafica a continuación:

“Nosotros regresamos acá (Pastoral) nos ayudan a nosotros [sic], de repente uno queda sin pega y uno regresa por ejemplo los sábados de salida, me vengo para acá, los fines de semana, las celebraciones que nos hacen acá de nuestros patronos, la navidad, la familia no hay donde ir y me vengo para acá, para mí es una ayuda”. (Mujer de nacionalidad boliviana, 29 años, residencia temporaria).

A partir del análisis de los grupos de discusión y entrevistas, se estima que la Pastoral de Migraciones de Iquique se constituye en una red de apoyo, en la medida que contribuye a enfrentar el problema de la vulnerabilidad social a la que se ven expuestos los migrantes fronterizos. Este vínculo que involucra trasformaciones en el espacio físico y simbólico de una parte de la ciudad y que se nutre, a través de sus quehaceres cotidianos, en valores y prácticas como la solidaridad, la reciprocidad y el paisanaje. Esto, se aprecia en el relato que mantienen los entrevistados, en tanto señalan el esfuerzo de la organización para mantener los vínculos permanentes con sus tradiciones a través de actividades simbólicas y recreativas. Sin embargo, más allá de la importancia como único dispositivo de acogida y apoyo en la llegada de los recién llegados, su presencia es decisiva para comprender las estrategias de inserción laboral y de acomodación en la ciudad. Ésta se caracteriza fundamentalmente por la precariedad, puesto que la organización tiene como soporte el voluntariado y estudiantes en prácticas de instituciones de educación superior. Por lo tanto, la mediación con otras instancias y la consecución de recursos es limitada a las donaciones de la Iglesia, organismos municipales y particulares. Estos factores impiden una inserción más amplia de los recién llegados hacia otra clase de redes más extensas que disminuyan la vulneración de derechos a las que se exponen especialmente en el arribo, aunque la Pastoral trabaja para evitarlo. 


\section{Conclusiones}

No cabe duda que el estudio de la migración fronteriza es un aspecto que ha cobrado interés en el último tiempo debido a la crisis económica en el hemisferio norte y a la búsqueda de nuevos destinos migratorios dentro del continente. En este contexto, Chile se ha convertido en un destino de los migrantes fronterizos en las últimas décadas tanto por la estabilidad política y económica, como por la brecha de desarrollo respecto de Bolivia y Perú. Así, las regiones colindantes -la actual Tarapacá y Arica-Parinacotase convierten en una puerta de entrada al país y en un espacio donde circular. Las crisis en distintas latitudes han relevado aspectos menos visibles pero no por ello inexistentes- en otras épocas migratorias, como son el retorno y la circulación como parte de un repertorio migratorio. Las asimetrías regionales y la cercanía, sin perder de vista los marcos jurídicos y la contingencia diplomática, convierten a las fronteras en un recurso y en una oportunidad. Su cruce permite alcanzar objetivos difíciles de cumplir en la comunidad de origen en un escenario donde la posibilidad del regreso favorece la aceptación de condiciones laborales y de vida con frecuencia precarios.

La inclusión del lugar de las redes sociales en el estudio de la movilidad fronteriza ha permitido revisar el lugar que ocupan las personas inmersas en la red, el uso de la información que por allí circula y la utilidad que presta a quienes acceden a ella. En este caso concreto, tanto el uso de las redes y en otros casos, el escaso acceso ellas, explica cómo se estructura la comunidad en destino, su composición y crecimiento. En el caso de Tarapacá, como plaza de la migración fronteriza femenina y como espacio de circulación, se aprecia una notoria canalización hacia oficios feminizados, especialmente de cuidado y de servicio doméstico. En este sentido la acción de la Pastoral como dispositivo de acogida, tiene la virtud de acoger a los recién llegados y de coadyuvar a cumplir de sus principales objetivos, a la vez que propende la incorporación laboral hacia nichos específicos. Así quienes llegan con apoyo de redes desde el origen o durante el cruce, construyen el proyecto migratorio en el camino, se informan de la existencia de la Pastoral configurándose como un dispositivo de acogida que los acompaña en la primera etapa de la migración. Cumplidos los objetivos o cuando las expectativas no se cumplen la posibilidad del retorno se mantiene, está allí.

De este modo se advierte que en los planes o proyectos migratorios de las mujeres que participaron en la investigación, el acceso o no a los recursos sociales de ayuda y de orientación de las redes de información, da lugar a estrategias migratorias distintas en la partida, el tránsito, el establecimiento y retorno, afectando en ocasiones a la duración de la empresa migratoria. La cercanía y la facilidad para acceder a la región por tierra, la demanda de mano de obra en nichos laborales específicos y la baja densidad de redes de apoyo -más allá de los amigos, los paisanos o la Pastoral- a las que acceden los recién llegados, afecta los modos de incorporación laboral a nivel regional. 
El marco jurídico modela más claramente las idas y venidas en la actual Arica-Parinacota de acuerdo al convenio Tacna y Arica. En el caso de Tarapacá, hasta previo al Acuerdo de Residencia de los Nacionales de los Estados Partes del MERCOSUR Bolivia y Chile de 2009, el trasiego fronterizo se explicaba por la entrada como turista y permanencia como tal hasta agotado el tiempo (90 días). Hacer frontera era una fórmula que les permitía sortear las dificultades normativas, especialmente cuando el plan no era quedarse o cuando no era posible conseguir un contrato de trabajo. El retorno era y sigue siendo el expediente en cualquier caso y una vez aprendido de los primeros viajes, las posibilidades de volver a Tarapacá se mantiene. De modo que en la región fronteriza las huellas de la frontera si bien existen, se mantienen y en ocasiones son más notorias, son conocidas y manejadas de manera activa por quienes la transitan habitualmente. Así más allá de los aspectos estructurantes de la migración se percibe la agencia en la experiencia migratoria, es decir, quienes deciden cruzar la frontera aprenden a moverse y a circular. Los constantes cruces, las estancias de duración variable, el retorno y el establecimiento, se constituyen en el largo plazo en un capital espacial en el sentido planteado por Tarrius (2000). Esa movilidad es facilitada por la contigüidad fronteriza que se constituye en un recurso, lo que configura una serie de movimientos donde el establecimiento, el tránsito y el regreso son parte de la misma empresa que no pone fin a la movilidad. Así quienes cruzan, por distintos motivos y en distintas direcciones, acumulan un acervo que les permite replicar nuevos cruces, nuevas empresas y nuevos objetivos.

Así las oportunidades que se abren en el espacio fronterizo, no son sólo el movimiento del que dan cuenta las cifras, sino la naturaleza de la movilidad y sus impactos sobre las dinámicas locales. De esta manera, las redes de información y apoyo representan un factor clave a la hora de analizar dicha naturaleza, ya que los fronterizos conscientes de sus limitaciones y de sus necesidades, cruzan la frontera de manera frecuente y construyen su vida en virtud de las oportunidades que se le manifiesta a uno y otro lado. De este modo el surgimiento de redes migratorias se densifica y construyen su propia territorialidad, al tiempo que se comportan como formas de soporte emocional y material, más menos fuertes en distintas ocasiones. Entonces, cuando los migrantes se incorporan en un principio a la sociedad receptora, estas redes se refuerzan y es cuando más se utilizan. Las mujeres que asisten a la Pastoral tienen mayor propensión a mantener los vínculos con la organización debido a que la movilidad es un rasgo permanente y los servicios que ofrece la organización- principalmente como intermediaria entre empleadores y las usuarias- es necesaria cada vez que cruzan la frontera. 


\section{Notas}

${ }^{1}$ Este trabajo se basa en los resultados de la tesis de pre-grado de Trabajo Social titulada Percepción de las mujeres inmigrantes usuarias de la Pastoral de Migraciones INCAMIIQUIQUE, en cuanto a su vinculación con las redes de apoyo en la región de Tarapacá, durante el segundo semestre del año 2011 y de los avances de investigación del Proyecto FONDECYT 11110096 a cargo de Marcela Tapia Ladino.

${ }^{2}$ INCAMI es la Fundación Instituto Católico Chileno de Migración que fue creado en 1925 por la Conferencia Episcopal Chilena para promover y realizar actividades de inserción e integración cultural de los migrantes.

${ }^{3}$ El año 2007 la Región de Tarapacá fue dividida para crear la XV Región de Arica-Parinacota.

${ }^{4}$ En la confección de mapas colaboró Dianela Arroyo, Geógrafa y Coordinadora Regional del Sistema Nacional de Coordinación de la Información Territorial SNIT de Tarapacá en el marco del trabajo de ayudantía del Proyecto FONDECYT No 11110096 y del Convenio del 28 de octubre de 2008 (D.E N ${ }^{\circ}$ 1571) entre el Gobierno Regional de Tarapacá y la UNAP.

${ }^{5}$ Ver: http://incami.cl/incami/historia/ Consultado el 22 de julio 2013

${ }^{6}$ Entrevista realizada al Padre Ildo Griz, coordinador del proyecto Tres Fronteras y colaborador en Pastoral de Migraciones de Iquique. Realizada el 12 de Diciembre de. 2011.

${ }^{7}$ En el proceso de regularización migratoria aplicado en Chile entre los años 2007 y 2008 se presentaron aproximadamente 55.000 solicitudes de las cuales 47.580 se resolvieron favorablemente. La mayoría de los beneficiarios fueron peruanos (35.071), seguidos de bolivianos (6.145), colombianos (2.003), ecuatorianos (1.958) y 2.403 provenientes de otros países (Texidó y Gurrieri, 2012).

${ }^{8}$ Estudios sobre migración y género advierten que la violencia hacia la mujer en contextos migratorios no es privativa de algunos colectivos, sino que es transversal y que no es posible estereotiparla en clases sociales o grupos migrantes (Darvishpour, 2003; Hyman, Guruge y Mason, 2008; Menjívar y Salcido, 2002). Asimismo se ha señalado la necesidad de considerar las características individuales de lo/as migrantes y los contextos en los que se produce la violencia para evitar generalizaciones (Menjívar y Salcido, 2002). En el mismo sentido y en un afán de ampliar la noción de violencia más allá del maltrato físico o el femicidio, es necesario atender a formas de control y subordinación que en muchas ocasiones son más difíciles de tipificar y por tanto son menos visibles (Tapia, 2011).

${ }^{9}$ Por este convenio los chilenos y peruanos que viajen con salvoconducto, primero y a partir de 2005 con DNI o carné de identidad pueden permanecer por periodos de hasta siete días en el Departamento de Tacna o en la Provincia de Arica respectivamente. Este permiso impide realizar actividades con fines de lucro como trabajo temporal o permanente, tampoco permite viajar más allá de los límites, es decir, más allá de la XV Región de AricaParinacota.

${ }^{10}$ Entre junio de 2008 y mayo de 2009 entraron y salieron 4.558.188 personas por las avanzadas o puestos fronterizos de la región, es decir, 438.364 más que por el Aeropuerto de Pudahuel y 2.755.727 más que por el Paso Internacional Los Libertadores De este estudio, se desprende que los peruanos usan este paso (Chacalluta) más aún que los propios chile- 
nos, y que sólo una fracción mínima de ellos va hacia Santiago, pues la gran mayoría utiliza el convenio de libre tránsito entre Tacna y Arica (852.960 entradas y 832.310 salidas) (Rozas, 5 de junio de 2009). 


\section{Bibliografía}

Aparicio, R. y A. Tornos (2005), Las redes sociales de los inmigrantes extranjeros en España. Un estudio sobre el terreno (Vol. 2). Ministerio de Trabajo y Asuntos Sociales, Madrid.

Arauco, E.; R. Mamani y J. Rojas (2007), Violencia contra la mujer en la pareja: respuestas de la salud pública en El Alto, Bolivia. CEPAL, Santiago de Chile.

Arauco, V. (2009), Informe Nacional sobre Desarrollo Humano 2009. El desafío urgente ante la asimetría departamental. PNUD, La Paz.

Ariza, M. (2000), Ya no soy la que dejé atrás... Mujeres migrantes en República Dominicana. Instituto de Investigaciones Sociales/Editorial Plaza y Valdés, México D.F.

Berganza, I. y M. Cerna (2011), Dinámicas migratorias en la frontera Perú-Chile. Arica, Tacna e Iquique. Fondo Editorial de la Universidad Ruiz de Montoya, Lima.

Camacho, G. y K. Hernández (2005), Cambió mi vida. Migración femenina, percepciones e impactos. UNIFEM/CEPLAES, Quito.

Cortes, G. (2000), Partir para quedarse. Superviviencia y cambio en las sociedades campesinas andinas de Bolivia. IRD/IFEA/Plural Editores, La Paz.

Ídem (2004), “Una ruralidad de la ausencia. Dinámicas migratorias en los valles interandinos de Bolivia en un contexto de crisis”. En Hinojosa, A., Migraciones transnacionales. Visiones de Norte y Sudamérica (pp. 167199). Plural Editores, La Paz.

Crespo, E. (2005), El inventario de la muerte.Feminicidio en Bolivia. Unifem/Red-Ada, La Paz.

Crossette, B. (2011), Estado de la población mundial 2011. 7 mil millones de personas, su mundo, sus posibilidades. Fondo de Población de las Naciones Unidas UNFPA, New York.

Darvishpour, M. (2003), Immigrant women challenge the role of men: How the changing power relationship within iranian families in Sweden intensifies family conflics after immigration. Journal of Comparative Family Studies, 33 (2), 271-296.

De La Torre, L. (2004), No llores, prenda, pronto volveré. Migración, movilidad social herida familiar y desarrollo. IFEA/PIEB/Universidad Católica Boliviana San Pablo, La Paz. 
Durand, J. (2000), “Origen es destino. Redes sociales, desarrollo histórico y escenarios contemporáneos”. En Tuiran, R.C. Migración México-Estados Unidos. Opciones de política (pp. 249-262). SRE/SG/CONAPO, México D.F.

Faist, T. (2000), “Transnationalization in international migration: implications for the study of citizenship and culture”. Ethnic and Racial Studies, 23, 189-222.

Faist, T. (2012), “Toward a Transnational Methodology: Methods to Address Methodological Nationalism, Essentialism, and Positionality”. Revue européenne des migrations internationales, 28 (1), 51-70.

González, J. A. (2008), “La emigración boliviana en la Precordillera de la Región de Antofagasta, 1910-1930. Redes sociales y estudios de casos”. Revista de Ciencias Sociales, 21, 61-85.

González, S. (1995), “Cochabambinos de habla quechua en las salitreras de Tarapacá”, 1880-1930. Chungará, Revista de Antropología Chilena, 27 (2), 135-151.

Ídem (2002), Hombres y mujeres de la pampa. Tarapacá en el ciclo de expansión del salitre. LOM, Santiago de Chile.

Ídem (2004), El Dios Cautivo. Las ligas patrióticas en la chilenización compulsiva de Tarapacá (1910-1922). LOM, Santiago de Chile.

Ídem. (2009), "La presencia boliviana en la Sociedad del salitre y la nueva definición de la frontera: Auge y caída de una dinámica transfronteriza (Tarapacá 1880-1930)”. Chungará, Revista de Antropología Chilena, 41 (1), 71-81.

Gonzálvez, H. y M. Tapia (2013), “Me voy a España a trabajar... familias migrantes colombianas, remesas económicas y relaciones de género en un contexto transnacional”. Chungara, Revista de Antropología Chilena, 45 (2).

Guaygua, G. y B. Castillo (2008), Atrapadas en las redes sociales. Prevención de la violencia familiar en El Alto, Quime Cochabamba y Santa Cruz. Centro de Promoción de la Mujer Gregoria Apaza, La Paz.

Gunderman, H. y H. González (2008), Pautas de integración regional, migración, movilidad y redes sociales en los pueblos Indígenas de Chile. Revista Universum, 23 (1), 82-115.

Gurak, D. y F. Caces (1998), "Redes migratorias y la formación de sistemas de migración”. En Malgesini, G. Cruzando fronteras. Migraciones en el sistema mundial (pp. 75-111). Icaria, Madrid. 
Hyman, I., S. Guruge y R. Mason (2008), “The Impact of Migration on Marital Relationships: A Study of Ethiopian Immigrants in Toronto”. Journal of Comparative Family Studies, 39-2, 149-163.

INE (2013), Resultados finales Censo 2012, en http://www.censo.cl/ Consultado el 30 de abril 2013

Jensen, F. (2013), “Atravesar» la frontera: La huella perpetua en la experiencia migratoria”. En Correa, V., I. Bortolotto y A. Musset, Geografías de la espera. Migrar, habitar y trabajar en la ciudad de Santiago, Chile. 1990-2012 (pp. 97-137). Fundación Scalabrini/Uqbar Editores, Santiago de Chile.

Jensen, M. (2009), “Inmigrantes en Chile: la exclusión vista desde la política migratoria chilena”. En Bologna, E., Temáticas migratorias actuales en América Latina: remesas, políticas y emigración (pp. 105-130). Asociación Latinoamericana de Población ALAP, Río de Janeiro.

Llopis, R. (2007), El “ ‘Nacionalismo metodológico’ como obstáculo en la investigación sociológica sobre migraciones internacionales”. Empiria. Revista de metodología de Ciencias Sociales, 13, 101-117.

Marcu, S. (2013), “La movilidad transfronteriza de rumanos en España en tiempos de crisis”. Revista Internacional de Sociología, 71 (1), 115-141.

Marteles, S. (2009), “Cooperación transfronteriza en la Triple Frontera de Bolivia-Chile-Perú”. En Rhi-Sausi, J.L. y D.C. Conato Cooperación transfronteriza e Integración en América Latina (pp. 175-215). IILA/CeSPI, Roma.

Massey, D., R. Alarcón, J. Durand y H. González (1991), Los ausentes. El proceso social de la migración internacional en el Occidente de México. México D.F.

Menjívar, C. (2000), Fragmented Ties: Salvadoran Immigrant Networks in America. University of California Press, Berkeley.

Menjívar, C. y O. Salcido (2002), “Immigrant Women and Domestic Violence: Common Experiences in Different Countries”. Gender and Society, 116, 898-920.

Morales, A. (2010), “Desentrañando fronteras y sus movimientos transnacionales entre pequeños estados. Una aproximación desde la frontera Nicaragua-Costa Rica”. En Anguiano, M.E. y A.M. López, Migraciones y frontera. Nuevos contornos para la movilidad internacional (pp. 185-224). Icaria, Barcelona.

Nicolao, J. (2011), Migraciones intrarregionales en Sudamérica, en http:/ /www.almendron.com/tribuna/34041/migraciones-intrarregionales-en- 
sudamerica/ Consultado el 15 de marzo 2011.

Norambuena, C. (2002), “Migraciones limítrofes. Chile 1865-1960”. En Asdrúbal, H. Historia de las migraciones limítrofes en el Cono Sur de América. Argentina, Bolivia, Brasil, Chile, Paraguay y Uruguay. Vol II Bolivia, Chile, Paraguay y Uruguay (pp. 25-90). Instituto Panamericano de Geografía e Historia, México D.F.

OEA (2012), Migración Internacional en las Américas. Segundo Informe del Sistema continuo de Reportes sobre Migración Internacional en las Américas (SICREMI). Organización de los Estados Americanos OEA, Washington D.C.

Payá, M.C. (2007), De los espacios de relación a las redes de inclusión: una vía de promoción de las mujeres inmigrantes. Ministerio de Trabajo y Asuntos Sociales, Madrid.

Pingol, A. (2001), Remaking masculinities: identity, power, and gender dynamics in families with migrant wives and househusbands. UP Center for Women's Studies: Ford Foundation, Quezon City.

Ídem (2004), "When gender identities become matters of choice”. En Sobritchea, C. y I.Y. Taehakkyo, Gender, culture and society (pp. 67-86). Ewha Womans University Press, Seoul, Korea.

PNUD (2005), Informe de Desarrollo Humano. Mapas Índice de desarrollo humano a nivel distrital por departamento. PNUD, Lima.

Ídem (2006), Las trayectorias del desarrollo humano en las comunas de Chile (1994-2003). Santiago de Chile: PNUD/Mideplan.

Ídem (2009), Informe sobre Desarrollo Humano 2009. Superando barreras: Movilidad y desarrollos humanos. PNUD, Nueva York.

Poggio, S. (2000), «Migración y cambio en las relaciones de género en las áreas metropolitanas de Washington y Baltimore» En Poggio, S. y O. Woo Migración femenina hacia EUA. Cambio en las relaciones familiares y de género como resultado de la migración (pp. 21-46). EDAMEX, México D.F.

Rivas, A.M., H. Gonzálvez, M.C. Medina, A. Rodríguez, M. Tapia, A. González, et al. (2008), El papel de las remesas económicas y sociales dentro de las familias migrantes transnacionales. Informe Final. Red Universitaria de Investigación en Cooperación.

Rosas, C. (2008), Varones al son de la migración. Migración internacional y masculinidades de Veracruz a Chicago. El Colegio de México, México D.F. 
Rozas, C. (5 de junio de 2009), "Extranjeros en Arica: las reveladoras cifras de la inmigración”. La Estrella de Arica.

Schmidt-Hebbel, K. (2006), “El crecimiento económico de Chile”. Banco Central de Chile. Documentos de trabajo, 365, 1-55.

Sinatti, G. (2008), “III. Migraciones, transnacionalismo y locus de investigación: multi-localidad y la transición de ‘sitios' a 'campos' ”. En Solè, C., S. Parella y L. Cavalcanti, Nuevos retos del transnacionalismo en el estudio de las migraciones (pp. 93-112). Ministerio de Trabajo e Inmigración, Madrid.

Ídem (2010), Mobile Transmigrants or Unsettled Returnees? Myth of Return and Permanent Resettlement among Senegalese Migrants. Population, Space and place, 17 (Journal Article), 153.

Solimano, A., V. Mellado, C. Araya, S. Lahoz y Y. Ocón (2012), Incorporación laboral de los migrantes en la Región Metropolitana de Chile. OIM, Santiago de Chile.

Stefoni, C. (2009), “Inmigrantes en Chile. Una integración diferenciada al mercado laboral”. En Migración y políticas sociales en América Latina. SOPLA/Konrad Adenauer, Brasil.

Ídem (2011), “Ley y política migratoria en Chile. La ambivalencia en la comprensión del migrante”. En Feldman-Bianco, B.; L. Rivera, C. Stefoni y M. Villa, La construcción social del sujeto migrante en América Latina. Prácticas, representaciones y categorías (pp. 79-109). CLACSO/FLACSO/ Universidad Alberto Hurtado, Santiago de Chile.

Tapia, M. (2010), Yo venía con un sueño... Relaciones de género entre inmigrantes de origen boliviano en Madrid. 2000-2007. Universidad Complutense/Instituto de Investigación José Ortega y Gasset, Madrid.

Ídem (2011), “La migración como escenario para la comprensión de la violencia de género entre migrantes internacionales”. Amérique Latine Histoire et mémoire, 21, En http://alhim.revues.org/index3733.html

Ídem (2012), “Frontera y migración en el Norte de Chile a partir del análisis de los censos de población. S. XIX y XXI”. Revista Geografía Norte Grande, 52, 177-198.

Ídem (2013), "Migración y movilidad de los trabajadores fronterizos en Tarapacá durante el ciclo del nitrato. 1880-1930”. En González, S., La sociedad del salitre: protagonistas, migraciones, cultura urbana y espacios públicos, 1870-1940 (pp. 163-194). RIL, Santiago de Chile.

Tapia, M. y C. Ovando. (2013), “Los Andes tarapaqueños, nuevas espacialidades y movilidad fronteriza ¿barrera geográfica o espacio para la inte- 
gración?” (en prensa). En Nuñez, A. y R. Sánchez Fronteras en movimiento e imaginarios geográficos. La Cordillera de los Andes como espacialidad socio-cultural, Instituto de Geografía, Pontificia Universidad Católica, Santiago de Chile.

Tarrius, A. (2000), “Leer, describir, interpretar las circulaciones migratorias: conveniencia de la noción de 'territorio circulatorio’. Los nuevos hábitos de la identidad”. Relaciones, 21 (83), 39-66.

Texidó, E. y J. Gurrieri. (2012), Panorama migratorio de América del Sur 2012. Organización Internacional para las migraciones OIM, Buenos Aires.

Tijoux, M.E. (2002), “Moderse la lengua. La dificultad de ser peruano en Chile”. Histoire \& Mémorie, 5, en http://alhim.revues.org/ index639.html\#tocto1n1 Consultado el 3 de diciembre 2010

Wimmer, A. y N.G. Schiller (2003), "Methodological Nationalism, the Social Sciences, and the Study of Migration: An Essay in Historical Epistemology”. International Migration Review, 37(3), 576-610.

Recibido: 28.05.2013

Aceptado: 25.07.2013 